\title{
Decisions Optimization Related to the Production Within Refining and Petrochemical Industry
}

\author{
Cătălin Popescu \\ Business Administration Department, \\ Petroleum-Gas University of Ploieşti, Ploieşti, Romania
}

\begin{abstract}
The paper underlines the use of quantitative analyses and mathematical models to optimize the decision within companies from oil and gas industry. It will be presented a case study from a refinery that use RPMS (Refinery and Petrochemical Modeling System) software for optimizing LPG blends.
\end{abstract}

Key Words: mathematical models, optimal solution, computer software, RPMS, oil and gas industry

\section{INTRODUCTION}

Many organizational problems requiring different managerial decisions have to call quantitative analyses defined by management science. Management science relies on mathematical modeling, a process that transforms some observed phenomena into mathematical expressions. Also, mathematical models translate important business problems into a form suitable for determining "an optimal solution by using computer software. Building useful mathematical models is a difficult and complex task and is related with the entire management science process.

This paper is focused on the subjects connected to the petroleum industry. This domain is linked to large projects and has to focus to use a team approach that capitalizes on the talents of the management science analyst as well as those coming from other relevant business disciplines. For instance, the models defining oil industry involve the purchase of crude oil and the manufacture and distribution of various grades of gasoline (upstream, middle-stream and down-stream processes) [1]. In this regard, the team responsible for building the model and evaluating its results could consist of some of the following: chemical engineer, economist, marketing analyst, financial officer, accountant, production manager or transportation specialist [1]. To facilitate and integrate the use of mathematical models in the decision processes, in different and complex industrial activities, are used powerful computer tools.

\section{Tools for optimizing the decision}

There are more than 20 commercially licensed languages and solvers used for optimization: AMPL, CPLEX, Excel Solver, GAMS, IMSL, MATLAB, MATHCAD, SAS, SCIP etc. For instance, Excel Solver Function is a Microsoft Excel add-in that can be used for evaluation analyzes. The solution will be used to find the optimal (maximum or minimum) value for a formula in a cell, called the objective cell, taking into account constraints or limit values in other cell types with formulas within the worksheet. The solver works with a group of cells, called decision variables or just variable cells, which are used to calculate formulas in objective and constrained cells. The solution adjusts values in decision-makers cells to meet boundaries imposed in constrained cells and produces the desired result in the objective cell [2]. 
Solver Parameters

Set Objective:

To:

( Max

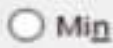

\section{sus25}

Yalue of:
0

By Changing Variable Cells:

Subject to the Constraints:
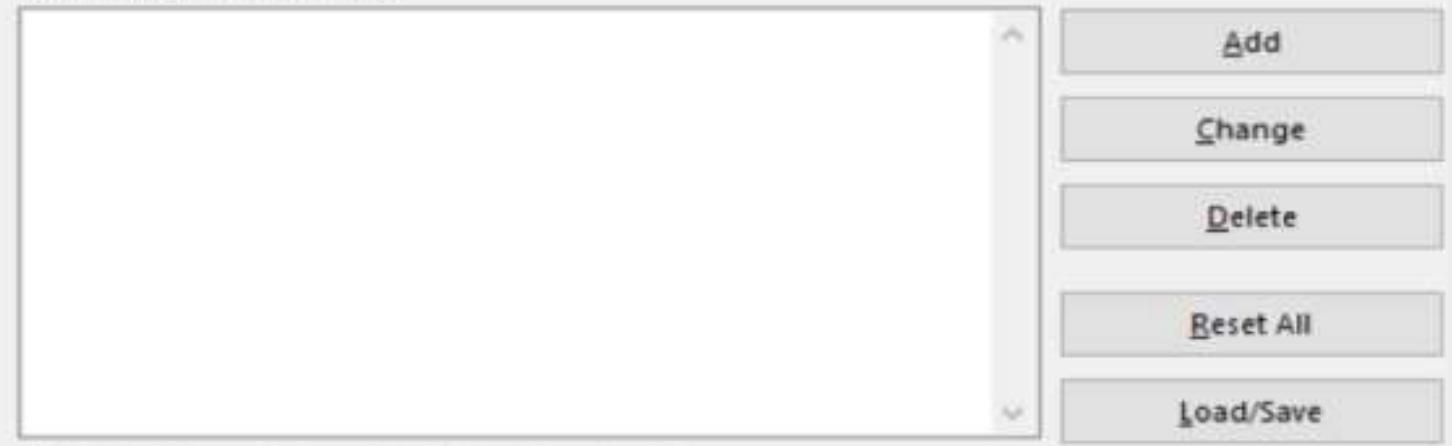

Make Unconstrained Variables Non-Negative

Select a Solving
Method:
Solving Method
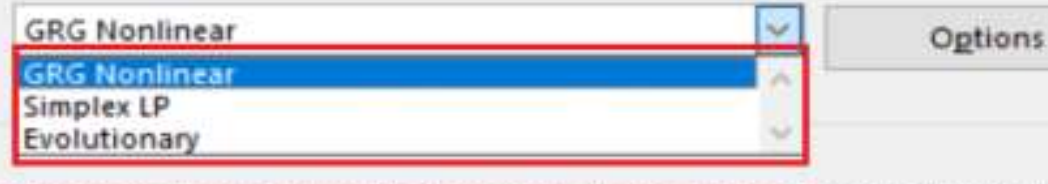

Select the GRG Nonlinear engine for Solver Problems that are smooth nonlinear. Select the LP Simplex engine for linear Solver Problems, and select the Evolutionary engine for Solver problems that are non-smooth.

\section{Help}

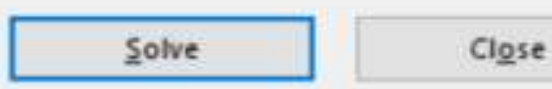

Fig.1 Set parameters in Excel Solver Function (capture from Microsoft Excel 2016)

The solver methods used by Solver are as follows:

1. Generalized Reduced Gradient (GRG) Nonlinear is used for non-linear problems;

2. Linear Programming Simplex is used for linear problems;

3. Evolutionary is used for strong non-linear issues $[2]$.

Another example is represented by FICO Xpress Optimization. The broad portfolio of FICO Xpress Optimization, in terms of optimization options, allows users to build, place and use optimization solutions that meet the requirements. The standard package includes performance solvers and algorithms, flexible modeling environments, fast application development, comparative scenario study and reporting capabilities and cloud installations. Solving a wide range of issues may be the difference between success and failure in today's market environment. FICO ${ }^{\circledR}$ Xpress
Optimization allows companies to solve their most difficult problems faster. Xpress Optimization consists of four components:

1. FICO Xpress Insight enables companies to quickly implement optimization models as powerful applications. This allows companies and other users to work with patterns in easy-tounderstand terms;

2. FICO Xpress Executor provides independent support for execution optimization services, enabling companies to deploy and run optimization models quickly and easily;

3. FICO Xpress Solver offers the widest range of industry-leading optimization algorithms and technologies to solve linear, mixed and nonlinear numerical problems;

4. FICO Xpress Workbench is an integrated development environment for developing optimization models, services and solutions. 
FICO ${ }^{\circledR}$ Xpress Workbench supports and is used with all other FICO Xpress Optimization components [3].

\section{Case study regarding the Implementation of RMPS software for optimizing LPG blends}

The RPMS software is used for strategic (long-term), medium and current (short term) planning. The recursive linear sequential programming (LP) recursive method is used to search for the solution of optimized production planning problems in RPMS systems [4]. To make the decision known to other organizational structures involved in the production process, economic and logistic analysis, RPMS generates a series of .xls (EXCEL) reports. In order to control the fulfillment of the production plan at least once a week, a meeting will be held with the staff involved in production and delivery management.

The demand for liquefied petroleum gas (LPG) is strongly influenced by the market price of gasoline (the LPG car being the alternative to gasoline for internal combustion engines adapted to the use of LPG) and has a pronounced seasonal character, so in the summer period the demand for LPG increases and decreases during the winter period[5]. The refinery produces 3 types of liquefied petroleum gas (LPG): automotive LPG, LPG type 3 and propylene, based on 4 components: propane, propylene, propane- butane and butane. The properties of the LPG components and their specifications are presented in Tables I and II [6].

TABLE I LPG components and properties

\begin{tabular}{|c|c|c|c|c|c|c|c|}
\hline \multirow{2}{*}{ Flow } & \multirow{2}{*}{ Production, $\mathrm{t}$} & \multicolumn{6}{|c|}{ Properties $\% g r$} \\
\hline & & $C 2, \% g r$ & $C 3, \% g r$ & $C 4, \% g r$ & $C 5, \% g r$ & Total, \%gr & C3, \%gr \\
\hline Propane & 3000 & $2 \%$ & $96 \%$ & $2 \%$ & $0 \%$ & $100 \%$ & $4 \%$ \\
\hline Propylene & 4000 & $1 \%$ & $97 \%$ & $2 \%$ & $0 \%$ & $100 \%$ & $96 \%$ \\
\hline Propane-butane & 800 & $1 \%$ & $40 \%$ & $58 \%$ & $1 \%$ & $100 \%$ & $0 \%$ \\
\hline Butane & 12200 & $0 \%$ & $3 \%$ & $95 \%$ & $2 \%$ & $100 \%$ & $2 \%$ \\
\hline TOTAL & 20000 & & & & $\theta$ & 7 & \\
\hline
\end{tabular}

TABLE II Specifications for LPG for cars, LPG type 3 and propylene

\begin{tabular}{|c|c|c|c|c|c|c|}
\hline \multirow{2}{*}{ Component } & \multicolumn{2}{|c|}{ LPG for cars } & \multicolumn{2}{|c|}{ LPG type 3} & \multicolumn{2}{|c|}{ Propylene } \\
\hline & $\min \% g r$ & $\max \% g r$ & $\min \% g r$ & $\max \% g r$ & $\min \% g r$ & $\max \% g r$ \\
\hline $\mathrm{C} 2$ & & $1 \%$ & & $1 \%$ & 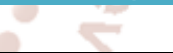 & 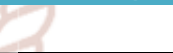 \\
\hline C3 & $36 \%$ & 45 & 2156 & $35 \%$ & 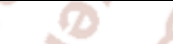 & \\
\hline $\mathrm{C} 4$ & 3 & & $60 \%$ & & 0 & \\
\hline $\mathrm{C} 5$ & 8 & $2 \%$ & & $3 \%$ & 2 & \\
\hline $\mathrm{C} 3^{\prime}$ & $\bar{D}$ & $12 \%$ & $800 \%$ & $35 \%$ & $95 \%$ & \\
\hline
\end{tabular}

Depending on the market demand and the season, the price of liquefied petroleum gas may vary. In the absence of logistical and production limitations, the refinery will maximize production of one of three types of LPG products at the expense of other types to maximize the profit.

In the following, it will be analyzed situations in which the price of one of the types of LPG products changes from one another, thus influencing the decision to add propylene to the LPG auto in order to optimize LPG mixtures. Changing the price of one of the practical components will result in two mixes of the three LPG products:

1. The content of propylene in the LPG for cars will be minimal;

2. The propylene content in the automotive LPG will be maximum ( $\max 12 \%$ according to the specification in table II).

Case 1 assumes that the sale of propylene as a separate product without additive in the LPG for cars will result in a maximum profit. In tables III to V, are presented the simulation results in the RPMS of Case 1, starting from the data in tables I and II. 
International Journal of Trend in Scientific Research and Development (IJTSRD) ISSN: 2456-6470

TABLE III Production of LPG for cars production (case 1)

\begin{tabular}{|c|c|c|c|c|c|c|}
\hline \multirow{2}{*}{ Flow } & \multirow{2}{*}{ Consumption, $\mathrm{t}$} & \multicolumn{5}{|c|}{ Properties, \%gr } \\
\cline { 3 - 7 } & & $C 2$ & $C 3$ & $C 4$ & $C 5$ & $C 3$ \\
\hline Propane & 3000 & $2 \%$ & $96 \%$ & $2 \%$ & $0 \%$ & $4 \%$ \\
\hline Propylene & 0 & $1 \%$ & $97 \%$ & $2 \%$ & $0 \%$ & $96 \%$ \\
\hline Propane-butane & 800 & $1 \%$ & $40 \%$ & $58 \%$ & $1 \%$ & $0 \%$ \\
\hline Butane & 5552 & $0 \%$ & $3 \%$ & $95 \%$ & $2 \%$ & $2 \%$ \\
\hline Total, t & 9352 & 68 & 3367 & 5798 & 119 & 231 \\
\hline Total, \%gr & & $0,73 \%$ & $36 \%$ & $62 \%$ & $1,27 \%$ & $2,47 \%$ \\
\hline
\end{tabular}

TABLE IV Production of LPG type 3 (case 1)

\begin{tabular}{|c|c|c|c|c|c|c|}
\hline \multirow{2}{*}{ Flow } & \multirow{2}{*}{ Consumption, $\mathrm{t}$} & \multicolumn{5}{|c|}{ Properties, $\%$ gr } \\
\cline { 3 - 7 } & & $C 2$ & $C 3$ & $C 4$ & $C 5$ & $C 3$ \\
\hline Propane & 0 & $2 \%$ & $96 \%$ & $2 \%$ & $0 \%$ & $4 \%$ \\
\hline Propylene & 0 & $1 \%$ & $97 \%$ & $2 \%$ & $0 \%$ & $96 \%$ \\
\hline Propane-butane & 0 & $1 \%$ & $40 \%$ & $58 \%$ & $1 \%$ & $0 \%$ \\
\hline Butane & 6648 & $0 \%$ & $3 \%$ & $95 \%$ & $2 \%$ & $2 \%$ \\
\hline Total, t & 6648 & 0 & 199 & 6316 & 133 & 133 \\
\hline Total, \%gr & & $0,00 \%$ & $3 \%$ & $95 \%$ & $2 \%$ & $2 \%$ \\
\hline
\end{tabular}

TABLE V Production of propylene (case 1)

\begin{tabular}{|c|c|c|c|c|c|c|}
\hline \multirow{2}{*}{ Flow } & \multirow{2}{*}{ Consumption, $\mathrm{t}$} & \multicolumn{5}{|c|}{ Properties, $\% \mathrm{gr}$} \\
\cline { 3 - 7 } & & $C 2$ & $C 3$ & $C 4$ & $C 5$ & $C 3$ \\
\hline Propane & 0 & $2 \%$ & $96 \%$ & $2 \%$ & $0 \%$ & $4 \%$ \\
\hline Propylene & 4000 & $1 \%$ & $97 \%$ & $2 \%$ & $0 \%$ & $96 \%$ \\
\hline Propane-butane & 0 & $1 \%$ & $40 \%$ & $58 \%$ & $1 \%$ & $0 \%$ \\
\hline Butane & 0 & $0 \%$ & $3 \%$ & $95 \%$ & $2 \%$ & $2 \%$ \\
\hline Total, $\mathrm{t}$ & 4000 & 40 & 3880 & 80 & 0 & 3840 \\
\hline Total, \%gr & & $1,00 \%$ & $97 \%$ & $2 \%$ & $0 \%$ & $96 \%$ \\
\hline
\end{tabular}

Case 2 assumes that the addition of propylene in the LPG for cars will reduce the amount of LPG type 3 and propylene put up for sale and increase LPG production and get a maximum profit. In tables VI to VIII, are presented the simulation results in the RPMS of Case 1, starting from the data in tables I and II.

TABLE VI Production of LPG for cars production (case 2)

\begin{tabular}{|c|c|c|c|c|c|c|}
\hline \multirow{2}{*}{ Flow } & \multirow{2}{*}{ Consumption, $\mathrm{t}$} & \multicolumn{5}{|c|}{ Properties, \% $\%$} \\
\cline { 3 - 7 } & & $C 2$ & $C 3$ & $C 4$ & $C 5$ & $C 3$ \\
\hline Propane & 3000 & $2 \%$ & $96 \%$ & $2 \%$ & $0 \%$ & $4 \%$ \\
\hline Propylene & 1360 & $1 \%$ & $97 \%$ & $2 \%$ & $0 \%$ & $96 \%$ \\
\hline Propane-butane & 800 & $1 \%$ & $40 \%$ & $58 \%$ & $1 \%$ & $0 \%$ \\
\hline Butane & 8065 & $0 \%$ & $3 \%$ & $95 \%$ & $2 \%$ & $2 \%$ \\
\hline Total, $\mathrm{t}$ & 13225 & 82 & 4761 & 8213 & 169 & 1587 \\
\hline Total, \%gr & & $0,62 \%$ & $36 \%$ & $62,10 \%$ & $1,28 \%$ & $12 \%$ \\
\hline
\end{tabular}

TABLE VII Production of LPG type 3 (case 2)

\begin{tabular}{|c|c|c|c|c|c|c|}
\hline \multirow{2}{*}{ Flow } & \multirow{2}{*}{ Consumption, $\mathrm{t}$} & \multicolumn{5}{|c|}{ Properties, \%gr } \\
\cline { 3 - 7 } & & $C 2$ & $C 3$ & $C 4$ & $C 5$ & $C 3$ \\
\hline Propane & 0 & $2 \%$ & $96 \%$ & $2 \%$ & $0 \%$ & $4 \%$ \\
\hline Propylene & 0 & $1 \%$ & $97 \%$ & $2 \%$ & $0 \%$ & $96 \%$ \\
\hline Propane-butane & 0 & $1 \%$ & $40 \%$ & $58 \%$ & $1 \%$ & $0 \%$ \\
\hline Butane & 4135 & $0 \%$ & $3 \%$ & $95 \%$ & $2 \%$ & $2 \%$ \\
\hline Total, t & 4135 & 0 & 124 & 3928 & 83 & 83 \\
\hline Total, \%gr & & $0 \%$ & $3 \%$ & $95 \%$ & $2 \%$ & $2 \%$ \\
\hline
\end{tabular}


International Journal of Trend in Scientific Research and Development (IJTSRD) ISSN: 2456-6470

TABLE VIII Production of propylene (case 2)

\begin{tabular}{|c|c|c|c|c|c|c|}
\hline \multirow{2}{*}{ Flow } & \multirow{2}{*}{ Consumption, $\mathrm{t}$} & \multicolumn{5}{|c|}{ Properties, \%gr } \\
\cline { 3 - 7 } & & C2 & C3 & C4 & C5 & C3 \\
\hline Propane & 0 & $2 \%$ & $96 \%$ & $2 \%$ & $0 \%$ & $4 \%$ \\
\hline Propylene & 2640 & $1 \%$ & $97 \%$ & $2 \%$ & $0 \%$ & $96 \%$ \\
\hline Propane-butane & 0 & $1 \%$ & $40 \%$ & $58 \%$ & $1 \%$ & $0 \%$ \\
\hline Butane & 0 & $0 \%$ & $3 \%$ & $95 \%$ & $2 \%$ & $2 \%$ \\
\hline Total, t & 2640 & 26 & 2561 & 53 & 0 & 2534 \\
\hline Total, \%gr & & $1 \%$ & $97 \%$ & $2 \%$ & $0 \%$ & $96 \%$ \\
\hline
\end{tabular}

We can see how the production of LPG assortments changes in both cases. Therefore, in case 2 were 3874 tons more LPG for cars, 2514 tons less LPG type 3 and 1360 tons less propylene. This difference in production of LPG products will underpin the economic analysis of the influence of LPG prices on the propylene addition decision in the automotive LPG (tables IX-XI and figures 2-4). The standard price of LPG for cars, LPG type 3 and propylene are $\$ 420 / \mathrm{t}, \$ 320 / \mathrm{t}$ and $\$ 600 / \mathrm{t}$, respectively.

TABLE IX Influence of price change for propylene on the decision to add propylene to LPG for cars

\begin{tabular}{|c|c|c|c|}
\hline Propylene price, $\$ / t$ & $\min \mathrm{C} 3^{\prime}, 10^{3} \$$ & $\max C 3^{\prime}, 10^{3} \$$ & $+1-, 10^{3} \$$ \\
\hline 585 & 8395 & 8422 & 27 \\
\hline 590 & 8415 & 8435 & 320 \\
\hline $\begin{array}{r}595 \\
\end{array}$ & 8435 & 8449 & 13 \\
\hline 600 & re $8455 n$ & Gle 8462 & 7 \\
\hline 601 & Re 8459 rich & an 8464 & 5 \\
\hline 602 & 8463 & hen 8467 & 4 \\
\hline 603 & 8467 & 8470 & 3 \\
\hline 604 & SS 8471 & 78472 & 1 \\
\hline 605 & 8475 & 8475 & 0 \\
\hline 606 & 8479 & 8478 & -2 \\
\hline 607 & 8483 & 8480 & -3 \\
\hline 608 & 8487 & 8483 & -4 \\
\hline 609 & 8491 & 8486 & -6 \\
\hline 610 & 8495 & 8488 & -7 \\
\hline 615 & 8515 & 8501 & -14 \\
\hline 620 & 8535 & 8515 & -21 \\
\hline
\end{tabular}


International Journal of Trend in Scientific Research and Development (IJTSRD) ISSN: 2456-6470

\section{thousands \$}

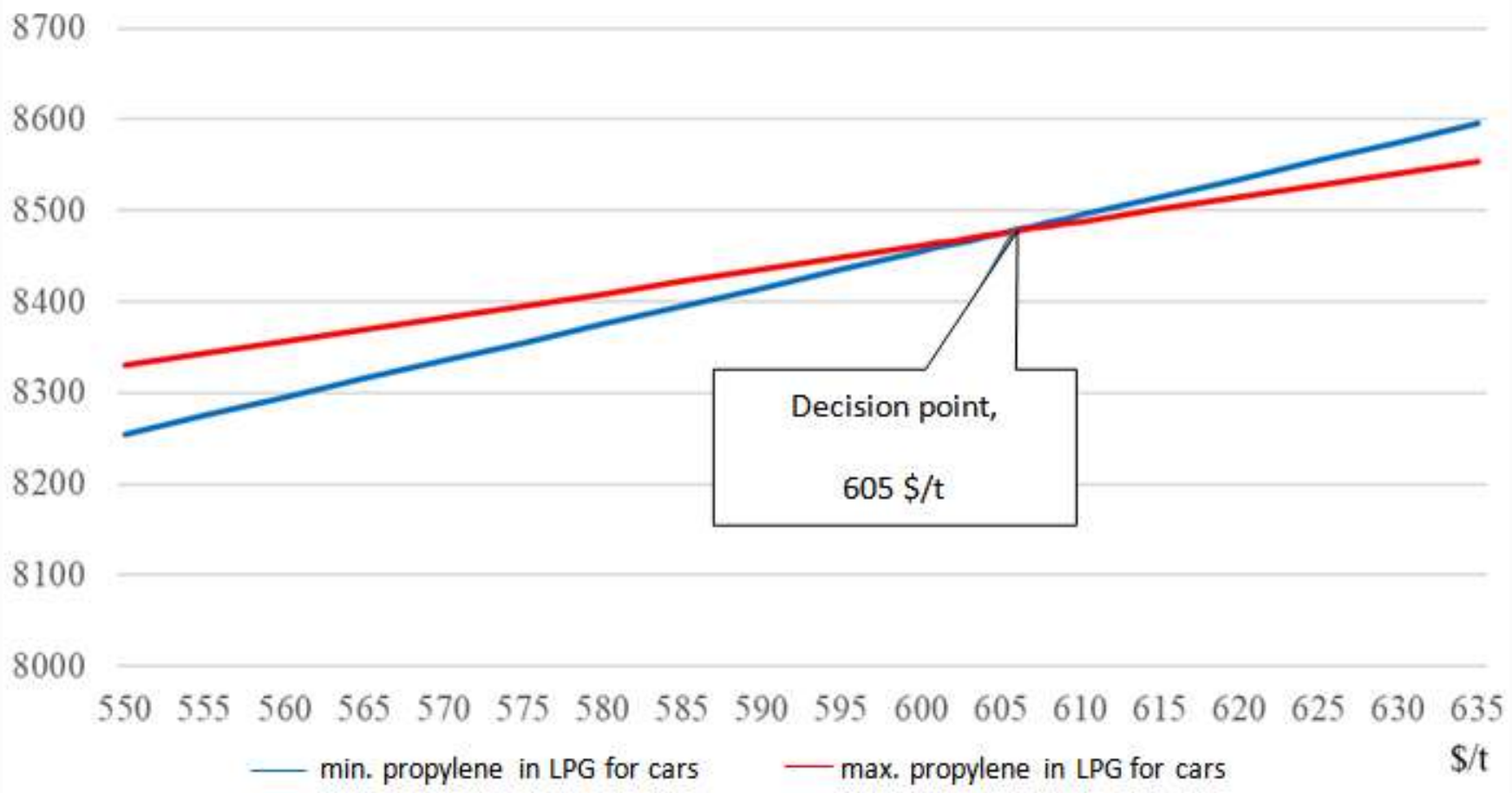

Fig.2 Influence of price change for propylene on the decision to add propylene to LPG for cars

By analyzing table IX and fig. 2 it shows that in the case of a propylene price below $605 \$ / \mathrm{t}$, the optimal decision will be to maximize the addition of propylene in the LPG for cars for maximum profit. Above $605 \$ / t$ it is recommended to minimize propylene in the LPG for cars.

TABLE X Influence of price change for LPG type 3 on the decision to add propylene to LPG for cars

\begin{tabular}{|c|c|c|c|}
\hline Propylene price,\$/t & $\min \mathrm{C} 3^{\prime}, 10^{3} \mathbb{\$}$ & $\max C 3^{\prime}, 10^{3} \$$ & $+/-, 10^{3} \$$ \\
\hline 310 & 8389 & 8420 & 32 \\
\hline 315 & 8422 & 8441 & 19 \\
\hline 320 & 8455 & 8462 & 7 \\
\hline 321 & 8462 & 8466 & 4 \\
\hline 322 & 8468 & 8470 & 2 \\
\hline 323 & 8475 & 8474 & -1 \\
\hline 324 & 8482 & 8478 & -3 \\
\hline 325 & 8488 & 8482 & -6 \\
\hline 330 & 8522 & 8503 & -19 \\
\hline 335 & 8555 & 8524 & -31 \\
\hline
\end{tabular}




\section{thousands $\$$}

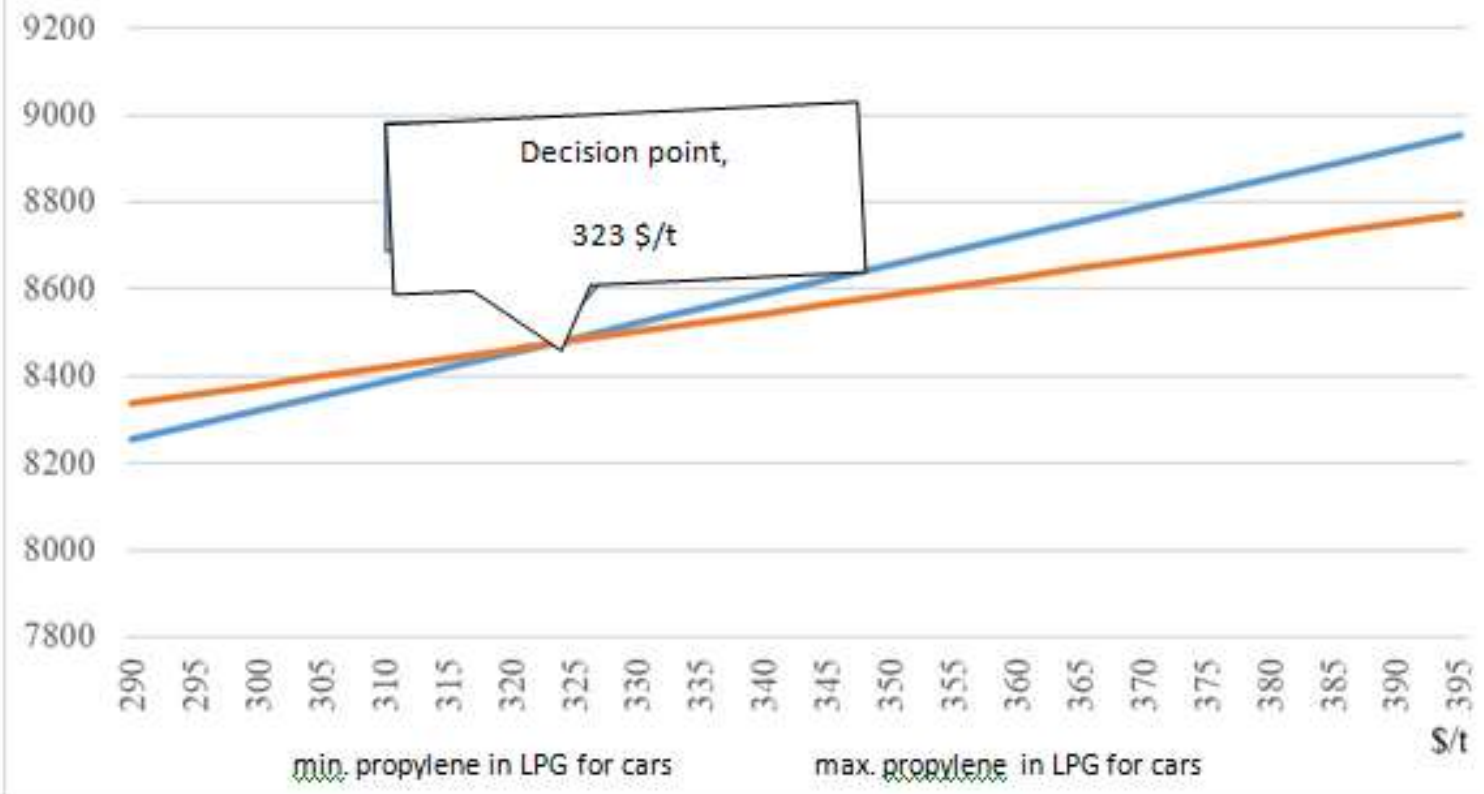

Fig.3 Influence of price change for LPG type 3 on the decision to add propylene to LPG for cars

Analyzing table $\mathrm{X}$ and fig. 3 , it follows that in the case of a price of LPG type 3 below $323 \$$ / t, the optimal decision will be to maximize the addition of propylene in the LPG for cars to maximize the profit.

TABLE XI Influence of price change for LPG for cars on the decision to add propylene to LPG for cars

\begin{tabular}{|c|c|c|c|}
\hline Propylene price, $\$ / t$ & $\min \mathrm{C} 3^{\prime}, 10^{3} \$$ & $\max C 3^{\prime}, 10^{3} \$$ & $+1-, 10^{3} \$$ \\
\hline 405 & 8315 & 8263 & -52 \\
\hline 410 & 8362 & 8329 & -32 \\
\hline 415 & 8408 & 78396 & -13 \\
\hline 416 & 8418 & 8409 & -9 \\
\hline 417 & 8427 & 8422 & -5 \\
\hline 418 & 8436 & 8435 & -1 \\
\hline 419 & 8446 & 8449 & 3 \\
\hline 420 & 8455 & 8462 & 7 \\
\hline 425 & 8502 & 8528 & 26 \\
\hline 430 & 8549 & 8594 & 45 \\
\hline
\end{tabular}




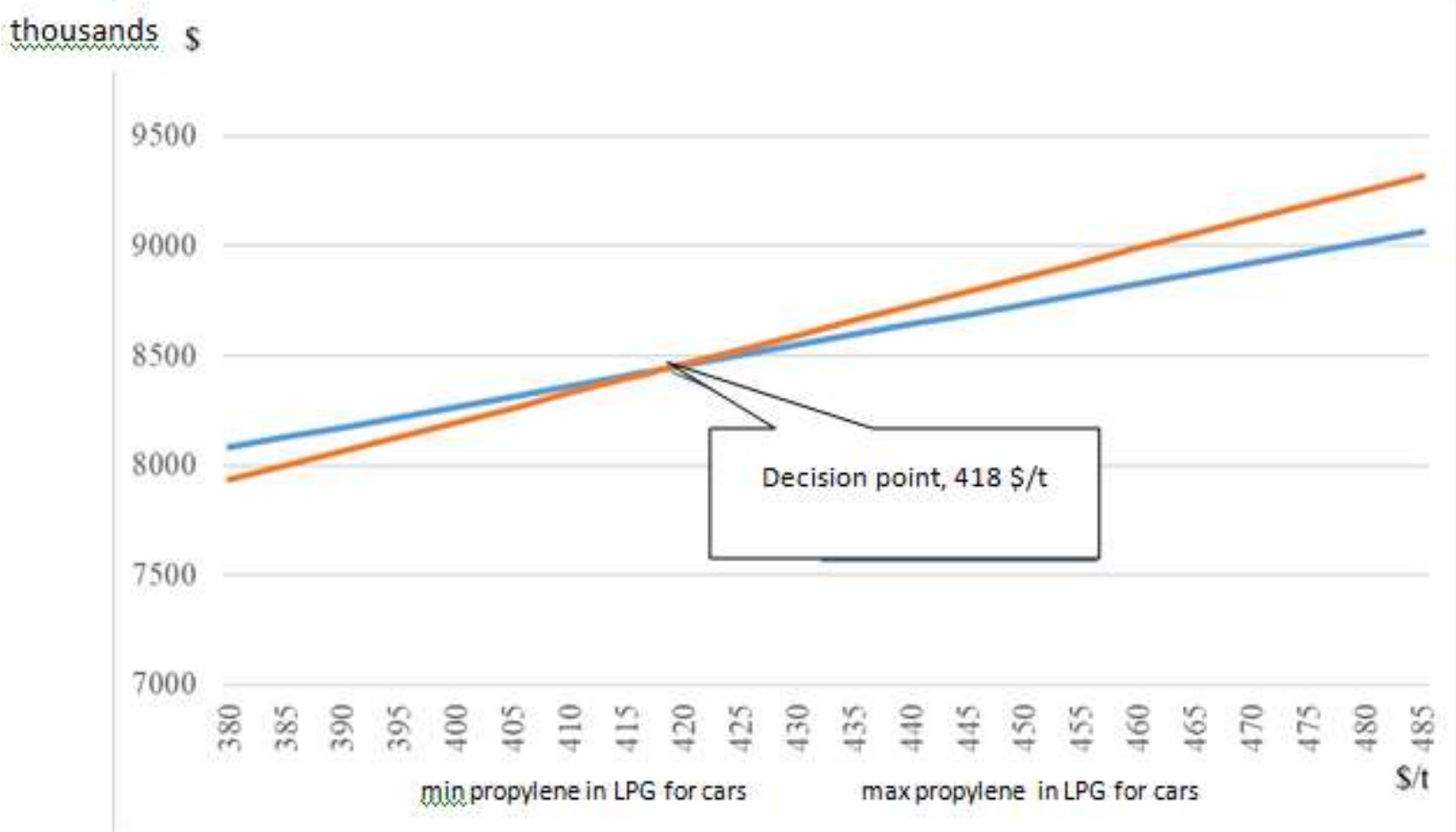

Fig.4 Influence of price change for LPG for cars on the decision to add propylene to LPG for cars

Analyzing table XI and fig. 4, it follows that in the case of a LPG price lower than $\$ 418 / \mathrm{t}$, the optimal decision will be to minimize the addition of propylene in the LPG for cars for maximum profit. Above 418 \$ / t it is recommended to maximize propylene in the LPG for cars.

\section{Conclusions}

In order to find out the optimal solution in a production matter, regarding the refining and petrochemical industry, there is useful to identify proper software that could assist the manager. Therefore this paper has exemplified the capabilities of RPMS (Refinery and Petrochemical Modeling System) software. The case study refers to optimizing LPG blends within a refinery. It was determined, taking in account different scenarios, the decision points in order to maximize the profit.

\section{References}

1. J. A. Lawrence, B. A. Pasternack, Applied Management Science: Modeling, Spreadsheet Analysis, and Communication for decision Making, John Wiley\&Sons, Inc. 2002, pp.5-27.
2. https://support.office.com/en-us/article/defineand-solve-a-problem-by-using-solver-5d1a388f079d-43ac-a7eb-f63e45925040

3. http://www.fico.com/en/products/fico-xpressoptimization\#overview.

4. _https://www.honeywellprocess.com/enUS/explore/products/advanced-applications/ software-productionmanagement/Pages/rpms.aspx.

5. E. Severin, Prezentare Planificarea optimizată a producției, baza de date PETRO-LUK S.A., Ploiești, 2016.

6. L.L.Lapin, W.D.Whistler, Quantitative decision making with spreadsheet applications, Thomson Learning, Belmont, USA, 2002, pp.325-329. 